\section{O papel do North Shopping no processo de integração metropolitana de Fortaleza e Caucaia}

Tiago Estevam Gonçalves* Maria Clelia Lustosa Costa**
RESUMO: Esta pesquisa tem como objetivo analisar o papel do North Shopping como elemento integrador da Região Metropolitana de Fortaleza, mais especificamente entre Caucaia e Fortaleza. O North shopping foi inaugurado em 1991, localizado na zona oeste de Fortaleza. Este estudo de abordagem regional, analisando o movimento pendular entre Caucaia e Fortaleza em função do trabalho e da escola encontra nas atividades do comércio, serviços e lazer, mais um elemento para justificar a intensificação deste movimento populacional cotidiano. Concluímos que este shopping tem contribuído para reforçar a relação entre Fortaleza e Caucaia.

\section{The role of the North Mall in the integration process and the Fortaleza metropolitan Caucaia}

\begin{abstract}
This research aims to analyze role of North Shopping as a integrator of the Fortaleza Metropolitan Region, more specifically betwen Caucaia and Fortaleza. The North Shopping was opened in 1991, located in the zone west of Fortaleza. This study of regional approach, analyzing the pendulum movement between Fortaleza and Caucaia due to work and school, find in the activities of trade, services and leisure, plus an element to justify the intensification of population movement everyday. We conclude that this mall has contributed to strengthening the relationship between Fortaleza and Caucaia.
\end{abstract}

*Professor do Instituto Federal de Educação, Ciência e Tecnologia do Ceará (IFCE). Possui Mestrado em Geografia pela Universidade Federal do Ceará. (UFC)

*** Professora do Departamento de Geografia da Universidade Federal do Ceará. Possui Mestrado em Geografia Humana pela Universidade de São Paulo (USP). Doutoranda em Geografia na Université Paris III.

\section{Palavras-chave: Movimento populacional; Integração metropolitana; Shopping center.}

Keywords: Population movement; Metropolitan integration; 


\section{Introdução}

A atividade comercial pode ocorrer em tipos básicos de edificações comerciais: lojas departamentos, galerias comerciais, mercados públicos. Ao analisarmos as organizações comerciais, sua evolução e as variadas formas destacamos o shopping center, como um sistema de comercialização moderno que alterou e altera a ordem urbana. Os shopping centers desenvolveram-se em meio aos avanços tecnológicos e em uma lógica de acumulação de capital que influenciou a sociedade urbana.

Os shopping centers, por sua vez, surgem na cidade, não mais nas periferias geométricas. Agora localizam-se no interior do tecido urbano, criando uma espécie de "ilhas tranquilas de consumo". Assépticos, seguros e isolados, os shopping centers são o refúgio da classe média que não suporta o desconforto e as inseguranças dos centros e subcentros tradicionais. (SILVA, 1998, p.33)

Neste contexto, na cidade de Fortaleza em meio à diversificação e expansão urbana surgem os shopping centers, que por sua vez, geraram e geram transformações no espaço urbano desta cidade como também em municípios próximos.

Fortaleza teve a implantação do primeiro shopping center em 1974, o Center Um, localizado no bairro da Aldeota, um dos primeiros subcentros de comércio da cidade, demonstrando assim o crescimento da cidade, que a partir desta década vai aos poucos deixando de ser monocêntrica (um centro comercial) transformando-se em policêntrica (vários centros comerciais).

Destacamos que, o processo de expansão da malha urbana de Fortaleza ultrapassou os limites municipais, ocasionando um novo fenômeno urbano-metropolitano - a metropolização do espaço, tendo interferência nas novas relações comerciais entre a capital e os munícipios próximos.

\footnotetext{
Um elemento ainda a destacar é que nesse aglomerado metropolitano a paisagem urbana revela que nas principais cidades multiplicam-se os centros comerciais (...) Junto aos eixos de maior circulação (...), centros comerciais, ligados ao grande capital comercial são construídos com seus hipermercados e shopping centers. (LENCIONI, 2005, p.39)
}

Na década de 1980 nasce na zona periférica da cidade de Fortaleza, o shopping Iguatemi. Já o North Shopping, surge em 1991, localizando-se em uma das principais vias que liga Fortaleza às cidades de sua Região Metropolitana. No final do século XX tivemos 0 aparecimento de muitos shoppings na cidade, principalmente nos bairros de classe média alta, contudo, os principais equipamentos são Iguatemi atendendo a classe média e média alta e 0 North Shopping atendendo um público de classe média e média baixa.

Nessa perspectiva, o objeto de estudo desta pesquisa é o North Shopping tendo como objetivo analisar o papel deste shopping no processo de integração de Fortaleza e Caucaia. Os

Geografia Ensino \& Pesquisa, v. 16, n.1, p. 55-70, jan./jun. 2012

O papel do North Shopping no processo de integração metropolitana de Fortaleza e Caucaia shopping centers no contexto urbano desenvolvem-se em meio à busca do capitalismo de novas formas de expansão e acumulação de capital. Sendo a cidade o local de produção e reprodução do capital, então, os shoppings instalam-se nela.

A cidade enquanto espaço de reprodução do capital. Nessa perspectiva, a cidade é condição geral da produção, e este de fato impõe uma determinada 
configuração ao urbano (...) formando uma aglomeração que, no capitalismo, tem em vista o processo de acumulação. (CARLOS, 1997, p.73)

Os shopping centers encontram nas cidades as estruturas sociais, econômicas e políticas. O capital atuou e atua na reorganização do espaço urbano. Cria e recria novas formas de acumulação. Nesta perspectiva podemos afirmar que o North Shopping seja reflexo dessa nova organização do espaço urbano, aparecendo como locus de consumo e lazer.

A partir disso pretendemos entender como o North Shopping tem interferido diretamente na integração metropolitana da Região Metropolitana de Fortaleza, principalmente entre Fortaleza e o município de Caucaia, mediante as atividades terciárias desenvolvidas pelo shopping.

Caucaia é o maior município da Região Metropolitana de Fortaleza em área, e é o segundo mais populoso. Localizado na parte Norte do Estado, distribui-se em uma área de 1.195,6 km² limitando-se ao Norte com o Oceano Atlântico; ao Sul com Maranguape; a leste com Maranguape, Maracanaú e Fortaleza e a oeste com São Gonçalo do Amarante e Pentecostes. O censo do Instituto Brasileiro de Geografia e Estatística (IBGE, 2010), registrou uma população de 324.738 habitantes.

Caucaia desempenha diferentes funções na Região Metropolitana de Fortaleza - RMF (lazer, residência, turismo, indústria), implicando em alto nível de integração com a metrópole, o que nos leva a buscar entender os porquês desta articulação.

No processo de metropolização desenvolvido depois da oficialização da RMF, em 1973, Caucaia tem progressivamente ampliado as relações sociais com a metrópole, através dos fluxos resultantes de atividades, trabalho, educação, lazer, dentre outros.

\section{Revisão de literatura}

No desenvolvimento teórico desta pesquisa estarão inseridos os conceitos: espaço geográfico, espaço urbano, região, região metropolitana, integração metropolitana, metrópole, cidade e shopping center.

Sobre o espaço geográfico Santos (1998, p.71) nos fala que:

O espaço seria um conjunto de objetos e de relações que se realizam sobre esses objetos; não entre estes especificamente, mas para as quais eles servem intermediários (...). O espaço é resultado da ação dos homens sobre o próprio espaço, intermediados pelos objetos, naturais e artificiais.

Neste contexto, o espaço urbano tem destaque, pois nele ocorre aglomeração das atividades do homem sobre o espaço. De acordo com Corrêa (2001, p.145) o espaço urbano permeia:

As relações sociais além de configurarem o espaço em um campo de lutas e um conjunto de símbolos, como dito anteriormente, também o configuram em fragmento, reflexo e condicionante social, desta forma adjetivando-o em espaço urbano.

A cidade como locus das relações sociais tende a expandir, com a sua expansão formam regiões que possuem uma dinâmica de fluxos de pessoas, mercadorias e informações. Contudo, temos diferenças entre região e região metropolitana, mesmo que estes dois conceitos estejam intrinsecamente relacionados, a priori destacaremos região, em seguida região metropolitana.

Geografia Ensino \& Pesquisa, v. 16, n.1, p. 55-70, jan.jun. 2012.

Gonçalves; T. E.; Costa, M. C. L. 
Milton Santos (1996) ressalta o poder regionalizante das atividades terciárias que se dá em função do comércio, pois este estende o raio de ação das cidades. Consideramos, então, que alguns empreendimentos como os shoppings exercem influências que às vezes ultrapassam 0 tecido urbano da cidade que está instalada, desse modo, atingindo cidades vizinhas.

Entendemos por região metropolitana como um conjunto de municípios, constituindo-se num importante aglomerado demográfico, o qual é possuidor de grande expressão política e econômica. Esta região é locus de aprofundamento dos processos econômicos e sociais.

Nas regiões metropolitanas temos o fenômeno de integração metropolitana. Baseando-se em Pequeno (2009), consideramos integração metropolitana como o adensamento de fluxos econômicos e populacionais. No espaço metropolitano ocorrem diferenças entre os indicadores de fluxos, densidades, características ocupacionais e desempenho de funções específicas que tornam claro o papel diferenciado dos municípios na participação desta dinâmica metropolitana.

Com relação à metrópole, Amora (1999) diz que a metrópole é a grande cidade resultante da modernização com grande diversificação funcional e que desempenha um importante papel na organização de um espaço regional ou nacional. É, portanto, um centro de produção e difusão de inovações cuja escala de operacionalização requer uma grande aglomeração.

Carlos (2004) afirma que, a metrópole assume a função de comando e de irradiação dos processos transformadores, bem como o lugar de onde se lê, de forma privilegiada, o mundo moderno.

Podemos considerar que a cidade de Fortaleza está desempenhando o papel de metrópole regional, pois nela concentram-se atividades econômicas, sociais, culturais, administrativas, assim polariza sua Região Metropolitana como todo o estado Ceará.

Em relação à metropolização, Santos (1998, p.78) nos diz que "o deslocamento populacional do rural para urbano tem tido como consequências concentração de população e da pobreza nas cidades, e nas décadas de 70 e 80 tem dado origem ao fenômeno de macrourbanização ou metropolização no Brasil".

Ao remetermos a definição de metropolização não podemos deixar de conceituar cidade, Carlos $(2004$, p.7) afirma que:

É uma construção humana, é um produto histórico-social acumulado, nesta dimensão aparece como trabalho materializado, ao longo do processo histórico e desenvolvido por uma série de gerações. Expressão e significado da vida humana, obra e produto, processo histórico cumulativo.

O homem através do trabalho transforma o espaço geográfico de acordo com suas necessidades de uso ou necessidades de valor. A concretização deste trabalho é a materialidade que se dá tanto nas rugosidades do passado como no presente.

Assim, a concretização é a cidade através de suas formas, funções, estruturas e processos. Estabelece, então, neste espaço o lócus de primazia de acumulação e (re) produção do capital. Contextualizando os fenômenos urbanos e os shopping centers Silva (1998, p. 33) nos diz que:

Geografia Ensino \& Pesquisa, v. 16, n.1, p. 55-70, jan.jun. 2012

O papel do North Shopping no processo de integração metropolitana de Fortaleza e Caucaia
Os shopping centers, por sua vez, surgem na cidade, não mais nas periferias geométricas. Agora localizam-se no interior do tecido urbano, criando uma espécie de "ilhas tranqüilas de consumo". Assépticos, seguros e isolados, os shoppings centers são o refúgio da classe média que não suporta o desconforto e as inseguranças dos centros e subcentros tradicionais. 
Concluindo tal sentença, os shopping centers apresentam características especificas de acordo com a Associação Brasileira de Shopping Centers- Abrasce, como: projeto arquitetônico, localização num único terreno de fácil acesso, área de estacionamento, áreas de acesso de entrega de mercadorias, ter um grupo de inquilinos que proporcione variedades de mercadorias, um ambiente com conforto, segurança.

\section{Os primeiros shoppings a nível mundial, nacional e local}

Os primeiros shoppings do mundo foram criados, por Edward $\mathrm{H}$. Bouton, nos Estados Unidos, em 1907. Na década de 20, aparecem as primeiras edificações com lojas de diversos ramos, operadas através de uma administração centralizada.

O Country Club Plaza foi inaugurado fora da área central de comércio, em 1923, no Kansas, Nichols. Este centro comercial não era propriamente um shopping center $^{1}$, mas reunia características semelhantes, como uma arquitetura estilizada. Nos anos cinquenta, surge o Mall ${ }^{2}$ - uma alameda, com lojas em ambos os lados. Esta é uma característica dos shoppings centers.

O primeiro lugar no ranking mundial em número de shoppings são dos Estados Unidos com mais de 43.000. No Brasil segundo a ABRASCE ${ }^{3}$, o país contava com um total de 408 shoppings no ano de 2010 estando no $10^{\circ}$ lugar no ranking mundial. (Gráfico 01).

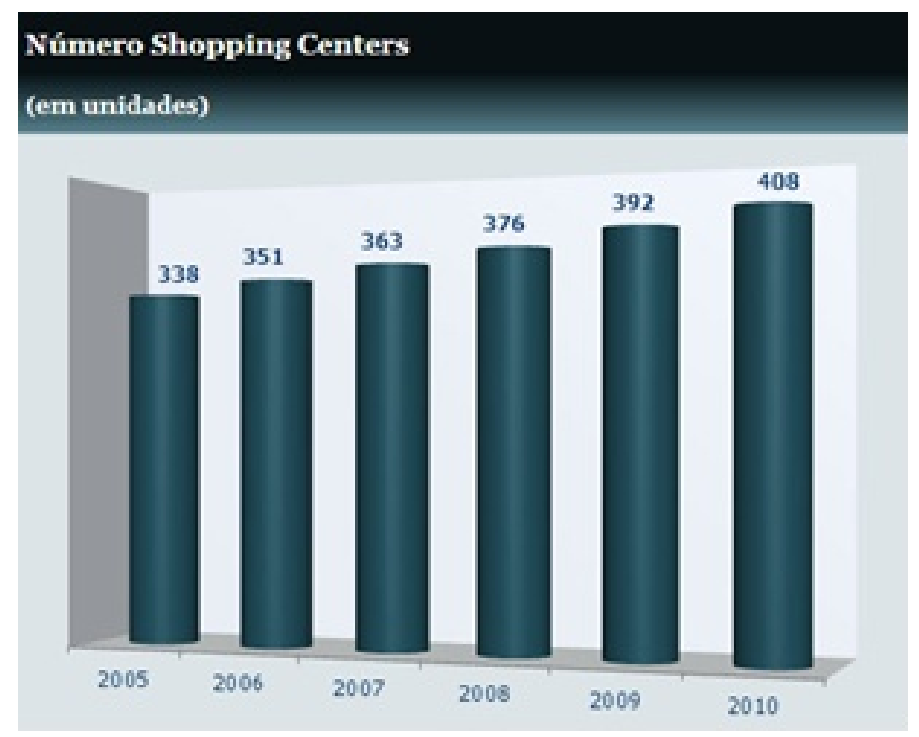

Gráfico 01- Evolução do número de shoppings no Brasil Fonte: http://www.abrasce.com.br

Os países europeus demoraram a aderir os shopping centers como estabelecimento comercial. Carvalho (2005) justifica que isto ocorreu a diversos fatores de ordem econômica e cultural. Dentre eles destacam-se: a falta de grandes terrenos disponíveis, a dificuldade de aprovar a construção destes imóveis junto aos órgãos competentes, leis de preservação do patrimônio histórico.

Na década de 1960, mais precisamente no ano de 1965 construíram na cidade de São Paulo um novo tipo de organização comercial tanto para o público quanto para o lojista, ou seja, uma modalidade de centro comercial - o shopping center.
1 Shopping center é um centro comercial planejado, sob administração única e centralizado, composto de lojas para locação com estacionamento próprio suficiente para atender as necessidades do empreendimento (ABRASCE).

${ }^{2}$ Mall - É um corredor de lojas do shopping center, que em ambos os lados, coberta ou descoberta, pode assumir vários formatos e constituindose numa área principal de circulação dos consumidores.

3 Associação Brasileira de Shopping Centers - ABRASCE, foi fundada em outubro de 1976, e tem como objetivo desenvolver pesquisas sobre a formação e manutenção e funcionamento dos shoppings, além de colaborar e aprimorar os shopping centers do Brasil.

Geografia Ensino \& Pesquisa, v. 16, n.1, p. 55-70, jan.jun. 2012.

Gonçalves; T. E.; Costa, M. C. L. 
A inauguração do primeiro shopping brasileiro - o Iguatemi, na cidade São Paulo, ocorreu em 27 de novembro de 1966. Entretanto, alguns autores divergem e afirmam que o primeiro shopping center foi instalado no Rio de Janeiro em 1964, no subúrbio do Méier (PINTAUDI, 1992).

Os shopping centers, segundo a Associação Brasileira de Shopping Centers se caracterizam por obedecer alguns critérios básicos: localização das atividades concentradas em um ponto previamente escolhido, resultado de pesquisas socioeconômicas sobre os hábitos dos consumidores, levando em consideração a idade, a renda e os tipos de produtos demandados pela coletividade de determinada área; planejamento técnico de localização dos ramos comerciais, ou seja, do "mix" do shopping, a fim de permitir uma distribuição adequada e a otimização do fluxo de compradores, com vistas a estimulá-los ou induzi-los às compras; e idoneidade e capacidade do grupo empreendedor de investimento que garantam a demanda dos empresários locatários e dos consumidores.

Além disso, estes grandes estabelecimentos comerciais precisam: da instalação de lojas âncoras, que se constituem em ponto de atração para o shopping; lojas compatíveis com a área bruta arrendável ao shopping, garantindo a influência e o escoamento tranquilo do fluxo dos automóveis; e de um sistema único de locação de lojas para manter o "mix" sempre inalterado, evitando a quebra do planejamento e o fluxo de compradores.

Na década de 1970 foram instalados shoppings nos estados do Paraná, Bahia, Minas Gerais e Ceará. $O$ número de shoppings no Brasil teve um aumento significativo em todo território, principalmente, a partir da década de 1980. O conforto, segurança e a oferta variada de produtos e serviços, principalmente os ligados ao lazer favorece este crescimento acentuado do número de shoppings no território brasileiro.

O espaço do shopping proporciona ao seu frequentador uma sensação de conforto, segurança e tranquilidade, dando-lhe liberdade para desfrutar das vitrines, e assim a criação de um imaginário consciente ou inconsciente de felicidade. A publicidade e o marketing favorecem a comercialização do produto, e as formas estratégicas de exposição atraem o consumidor.

No que tange ao aparecimento dos shoppings em Fortaleza, o Center Um, inaugurado em 1974, no bairro da Aldeota, foi o primeiro shopping center instalado no estado do Ceará. Em torno do Center Um, outros equipamentos comerciais e institucionais foram instalados, o que favoreceu a formação de um dos primeiros subcentros nesse bairro de Fortaleza.

Na zona sul, desenvolveu-se outro subcentro no bairro do Montese. Neste momento iniciase o processo de descentralização da cidade Fortaleza, o centro tradicional passa por mudanças de parte de suas funções.

No bairro Edson Queiroz, zona sudeste foi construído na década de 1980, o shopping Iguatemi, que já tinha estabelecimentos em outros estados brasileiros. Este equipamento e outros contribuíram para a expansão de Fortaleza para zona sudeste, onde se concentram comércios e serviços de luxo.

$\mathrm{Na}$ zona oeste, o primeiro shopping de grande porte foi inaugurado em 1991- o North Shopping. Localiza-se na Avenida Bezerra de Menezes, uma das principais vias que liga bairros da periferia e os municípios de Caucaia e São Gonçalo do Amarante da RMF ao centro da capital. Ao longo desta via já se desenvolvia um setor de comércio e serviços ainda incipiente que atendia aos bairros próximos, assim como, docentes e discentes da Universidade Federal do Ceará - UFC. Aos poucos, o comércio desta área ganhou destaque no desenvolvimento urbano-metropolitano. 
Esta forma de atividade comercial concentrada agrada a população. Vários tipos de shoppings surgem na cidade, com características variadas, de acordo com o público a que se destina. Uns com mais luxo e produtos de melhor padrão para atender as classes mais abastadas, enquanto outros mais simples em vários bairros, inclusive no centro da cidade, que atende as classes menos abastadas.

Em Fortaleza, inúmeros shoppings estão espalhados por vários bairros, embora sua maioria se localize nos bairros de classe média e média alta. Isto evidencia o processo de segregação socioespacial embutido no desenvolvimento desta nova forma de espaço de consumo.

Na capital, além dos shoppings já citados destacam-se outros frequentados pela classe média, principalmente, nos bairros da aldeota e Meireles: Avenida Shopping, Park Side Shopping, Shopping Dom Luís, Shopping Casa Blanca, Shopping Aldeota, Shopping Del Paseo. Nos bairros Edson Queiroz e Alagadiço, depois da implantação do Iguatemi, surgiram vários shoppings e lojas ocupando grandes superfícies: Shopping Salinas (shopping da casa), Casa Freitas, etc.

Na zona periférica do centro tradicional da cidade, destaca-se o Shopping Benfica, no bairro do mesmo nome, atende ao polo educacional e cultural que se desenvolveu em torno da Reitoria e centro de humanidades da UFC.

Estes vários shoppings apresentam especificidades, quanto ao tipo de lojas e equipamentos de lazer $\mathrm{O}$ Iguatemi, maior shopping da cidade, atende a uma classe média e média alta. Conta com várias lojas âncoras (C\&A, Lojas Americanas, Riachuelo, Renner, etc.), agências bancárias públicas e privadas, posto dos Correios e Telégrafos, e com lojas de grifes de renome no mercado nacional e internacional, atraindo desta forma os consumidores mais sofisticados.

Os shoppings Del Paseo e Aldeota são de menor porte quando comparados com o Iguatemi, mas têm uma grande importância no contexto comercial da cidade. Localizados nos bairros "nobre" da Aldeota atendem classes mais abastadas.

\section{Caracterização do North Shopping: cores e formas}

O North Shopping está localizado na Avenida Bezerra de Menezes, no bairro Presidente Kennedy, na cidade de Fortaleza-CE. No seu entorno destacam-se grandes equipamentos como o Campus do Pici da Universidade Federal do Ceará, o Colégio Santa Isabel, Colégio Máster, Colégio Joaquim Nogueira, Casas Freitas e Bancos do Brasil, Caixa Econômica Federal, Itaú, Real, Unibanco e Bradesco.

Além de inúmeros outros comércios e serviços, destacam-se restaurantes e bares que atendem a demanda da população local, composta também por estudantes, professores e funcionários que trabalham nas proximidades. Este shopping funciona de segunda à sexta das 10 às $22 \mathrm{~h}$, sábado das 9 às $22 \mathrm{~h}$ e domingo das 14:30h às 20:30h. Aos domingos a praça de alimentação/lazer abre às $11 \mathrm{~h}$.

Fundado em 1991, é considerado por seus empreendedores Sérgio Gomes e Fauzi Hamuche como um empreendimento de sucesso, pois conquistou o público fortalezense, caucaiense e de outras cidades da RMF. De acordo com levantamentos o North Shopping consegue atrair cerca de 14,5 milhões de visitantes anualmente.

Geografia Ensino \& Pesquisa, v. 16, n.1, p. 55-70, jan.jjun. 2012.

Gonçalves; T. E.; Costa, M. C. L. 
4 Loja âncora é 0 estabelecimento que atrai 0 número de consumidores para um shopping center. Ela deve ser bastante forte, a fim de atrair os consumidores residentes além dos limites da área de influência comercial.
O North Shopping conta com cinco pisos de estacionamento coberto, seis salas de cinema no conceito multiplex, 11 lojas âncoras ${ }^{4}$, serviços bancários (agência do Banco Real, um posto avançado do Banco do Brasil e caixas eletrônicas dos bancos Itaú e Bradesco). Neste shopping são realizadas diariamente mais de 300 operações comerciais.

O shopping oferece vários serviços e produtos como artigos esportivos, calçados e bolsas, artigos de bebê, moda feminina, moda infanto-juvenil, artigos de informática, artigos religiosos e esotéricos, brinquedos, eletroeletrônicos, móveis. Conta com agências de viagens, livrarias, papelarias, farmácia, restaurantes, lanchonetes.

$\mathrm{Na}$ área de entretenimento destacam-se: seis salas de cinema, parque infantil e ambientes com games, lanhouse e boliche. (o North Bowling Center tem oito modernas pistas de boliche, numa área de $525 \mathrm{~m}^{2}$ ). Além disso, o North Shopping tem um Autorama, contendo 8 modernas pistas com 14 metros de comprimento. De acordo com a administração é o maior da cidade de Fortaleza. Possui um sistema computadorizado que mostra instantaneamente a pontuação dos jogadores, exibindo o tempo e a velocidade de todos.

O Parque de Diversão tem vários brinquedos, jogos, games atendendo a um público infantil e de adolescentes: vídeo games, kidplay, Condor, boliche, basquete, xícaras, carrinhos. Este setor dispõe também de uma área reservada para festas infantis.

Na praça de alimentação encontram-se vários restaurantes, choperia e fast food. Próximo do boliche possui uma praça com telão, quiosques de alimentação, que oferecem pastel \& pizza, sushi e uma choperia, com cardápio variado, além de música ao vivo, todas as sextas e sábados, a partir de $18 \mathrm{~h}$.

O North Shopping, desse modo, apresenta-se como locus de consumo e lazer. Diante do sucesso desse empreendimento, o shopping passou por várias ampliações para atender a grande demanda da população da zona oeste de Fortaleza e de bairros de Caucaia.

\section{Perfil dos frequentadores do North Shopping}

Com o objetivo de analisar o papel do North Shopping na integração metropolitana realizamos a aplicação aleatória de 100 entrevistas com os frequentadores do shopping em análise. Buscamos construir um perfil destes frequentadores, coletando dados sobre idade, sexo, profissão, renda mensal e bairro ou município de origem. Perguntamos também os motivos que os levavam a frequentar esse shopping, seus principais atrativos, os dias que frequentavam e o meio de transporte.

Tabulados os dados chegamos as seguintes conclusões sobre o perfil socioeconômico dos frequentadores do North Shopping. Constatou-se que 60\% são mulheres e $40 \%$ homens. É significativa a presença de moradores de Caucaia 17\% e 73\% são de Fortaleza (Gráfico 2).
Geografia Ensino \& Pesquisa, v. 16, n.1, p. 55-70, jan.jjun. 2012

O papel do North Shopping no processo de integração metropolitana de Fortaleza e Caucaia 


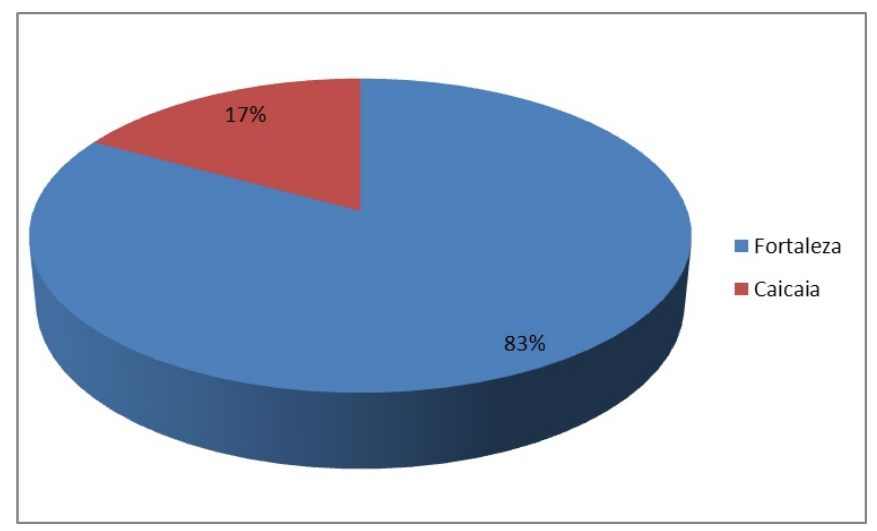

Gráfico 2 - Local em que habita

Ao analisarmos a faixa etária, observamos a predominância de jovens (38\%) e adolescentes (35\%), a presença de adultos (19\%), sendo pequena a participação de idosos (2\%) (Gráfico 3).

A maioria dos entrevistados se enquadrou nos segmentos jovens de 20 a 29 anos, logo em seguida adolescentes entre 14 e 19 anos, depois estão os adultos de 30 a 59 anos, e cerca de $6 \%$ dos frequentadores é formado por crianças ( 0 a 8 anos) e pré-adolescente (8 até 13 anos), por fim são poucas as pessoas idosas, acima de 60 anos que frequentam o shopping.

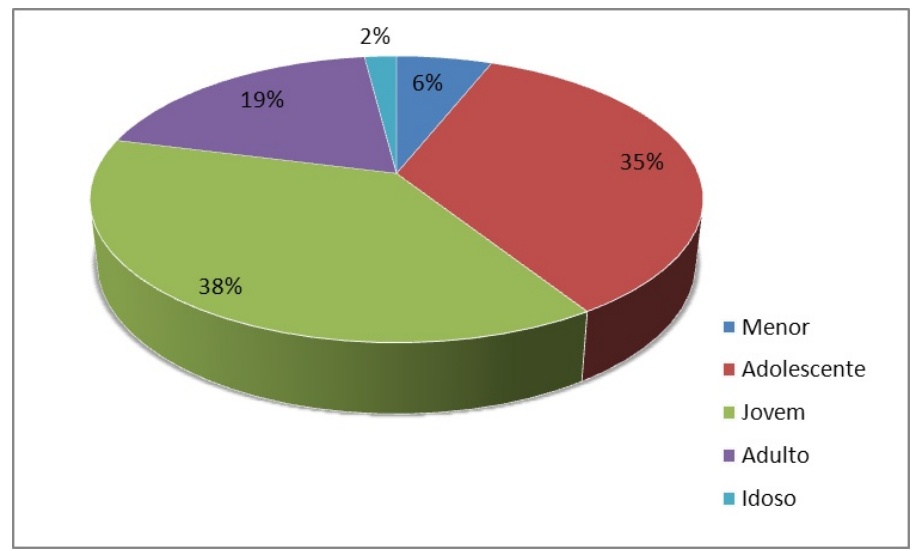

Gráfico 3 - Faixa etária

Outro elemento avaliado foi o poder aquisitivo da população frequentadora do North Shopping. Constatamos que predominam consumidores de baixa renda, aproximadamente $40 \%$ ganham menos de um salário. Cerca de $38 \%$ dos entrevistados ganha de um a dois salários mínimos, cerca de $13 \%$ entre dois e três salários, $8 \%$ ganham entre três e cinco salários e somente $1 \%$ acima de cinco salários (Gráfico 4). 


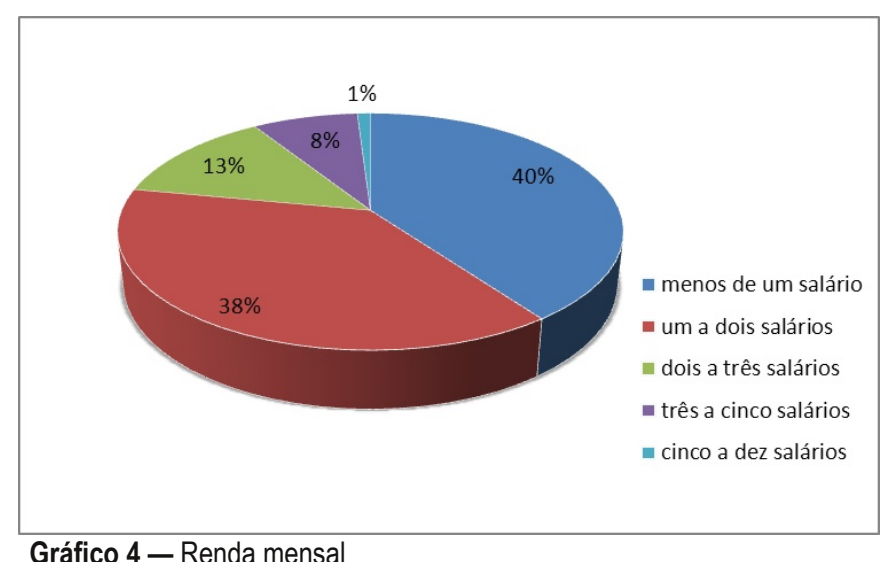

Outra preocupação nas entrevistas foi captar o objetivo da ida ao shopping. Cerca de $51 \%$ justificou que o shopping era um local propício para as compras pela diversidade de artigos que oferece. No que se refere à atividade de lazer cerca de $32 \%$ dos entrevistados afirmaram que quando não se deslocam para comprar vão à busca de lazer (cinemas, jogos, boliche, autoramas) e da praça da alimentação. Eles consideram o North shopping um ambiente de múltiplas opções para o divertimento (Gráfico 5).

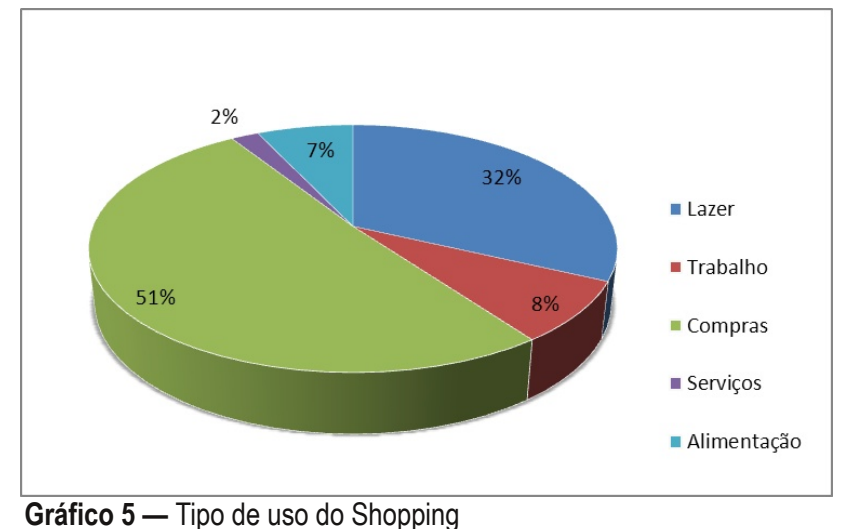

Perguntados sobre os elementos mais atrativos do North Shopping, 58\% afirmaram que era a grande variedade de lojas, que oferecia mais possibilidades de escolha ao consumidor. A configuração do shopping também facilitava consumo. Logo em seguida, $28 \%$ dos frequentadores disseram que 0 item segurança era fundamental. $O$ North Shopping apresentase como um local em que podem transitar seguros (Gráfico 6).

Geografia Ensino \& Pesquisa, v. 16, n.1, p. 55-70, jan./jun. 2012

O papel do North Shopping no processo de integração metropolitana de Fortaleza e Caucaia

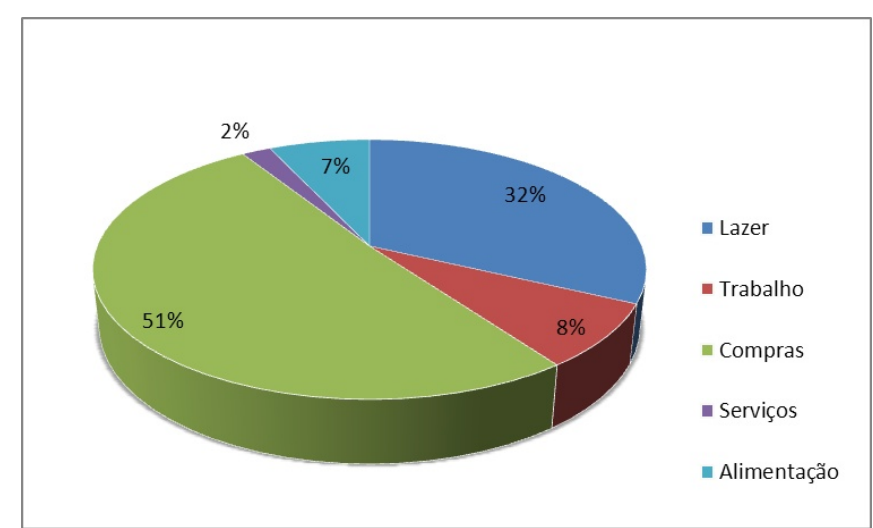

Gráfico 6 - Elemento atrativo do shopping 
A maioria dos frequentadores se desloca de casa para o North Shopping, mediante transporte coletivo (ônibus), ou seja, $80 \%$, o que revela o perfil socioeconômico dos consumidores. Somente $18 \%$ utiliza transporte individual, sendo $7 \%$ se transportam de moto e $11 \%$ de automóvel privado (Gráfico 7).

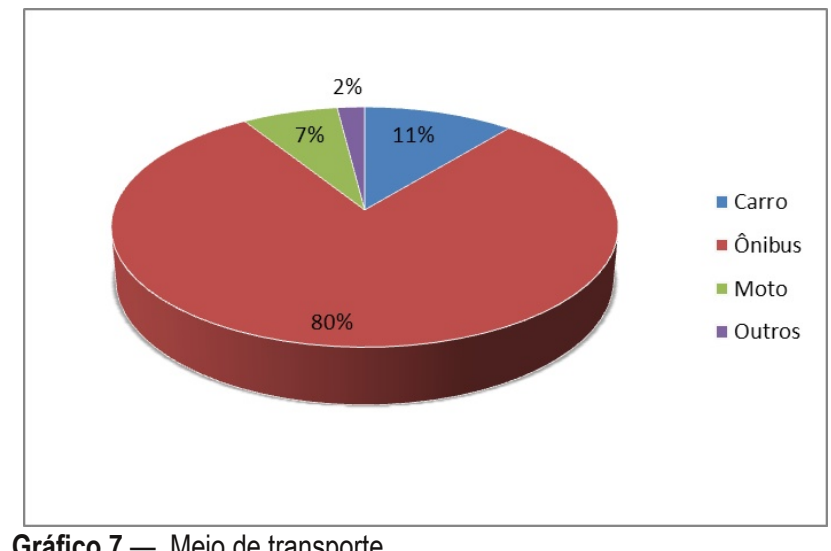

Gráfico 7 - Meio de transporte

O North Shopping ao ser comparado aos outros shoppings foi avaliado por $91 \%$ dos entrevistados como bom. Foi considerado por $4 \%$ excelente e por $5 \%$ regular. Ninguém 0 considerou péssimo (Gráfico 8).

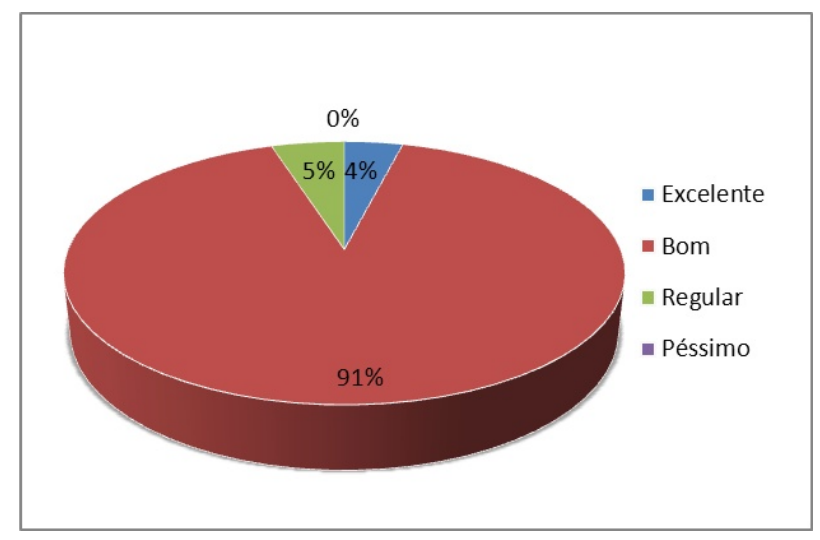

Gráfico 8 - Avaliação do North Shopping

A construção da imagem do North Shopping pelos meios de comunicação de massa induz as pessoas ao consumo, aparecendo no contexto urbano-metropolitano como signo de felicidade. É importante compreender o poder contagiante do consumo, tanto através do espaço de consumo (locus de compras) como através do consumo do espaço (locus de lazer). Esta euforia do consumo na sociedade contemporânea pode ser vista como a capacidade dos shoppings em conduzir os indivíduos a uma alienação, mediante ao consumo, ou seja, este equipamento revela-se como um verdadeiro templo de consumo, classificando-o desse modo pela grande maioria de seus frequentadores como um bom shopping.

A vitrine é o lugar de conexão de nossas práticas urbanas consumidoras, é também, por excelência, o lugar daquela comunicação e daquela troca de valores por onde todos se sentem iguais, os objetos e os produtos aí se oferecem numa encenação gloriosa, numa ostentação socializante. (CARVALHO, 2005, p.80)

Geografia Ensino \& Pesquisa, v. 16, n.1, p. 55-70, jan.jun. 2012.

Gonçalves; T. E.; Costa, M. C. L. 
Pelas vitrines, com suas formas, cores, luzes e materiais, captamos os simbolismos e as mensagens que querem transmitir. Uma imagem criada pelos especialistas em publicidade tem como finalidade potencializar a comercialização de produtos e serviços.

\section{Área de influência do North Shopping}

A área de influência de um shopping é maior em suas proximidades e diminui à medida que a distância aumenta. Os consumidores e frequentadores destes empreendimentos dão preferência a certos shoppings em função do acesso, distância, conforto, qualidade dos produtos e também da imagem construída pela publicidade.

Conforme Carvalho (2005), a área de influência pode ser dividida em três zonas distintas:

- Área de Influência Primária corresponde à área situada a cinco minutos de carro e representa, em média, a $70 \%$ da área de influência de um shopping center.

- Área de Influência Secundária corresponde à área situada entre 5 e 15 minutos de carro, e representam em média $20 \%$ da área de influência de um shopping center.

- Área de Influência Terciária corresponde à área situada a mais de 30 minutos de carro, do shopping center.

A localização estratégica do North Shopping na avenida Bezerra de Menezes favoreceu a formação de uma grande área de influência, atraindo consumidores não só dos bairros vizinhos, mas também da RMF. $\mathrm{O}$ acesso, tempo de deslocamento, facilidade de estacionamento e atrativos oferecidos, tais como a grande variedade de produtos oferecidos tem ampliado o poder de atração deste shopping.

Os primeiros fatores que influenciam na área de atração do North Shopping são: a ausência de barreiras, o curto tempo de duração das viagens e a "obrigatoriedade" de quase todas as linhas de ônibus e veículos que partem de Caucaia em direção a Fortaleza passarem em frente ao North Shopping, tem contribuído para exercer uma forte atração dos moradores deste município. É mais fácil e rápido se chegar ao North Shopping partindo de Caucaia a sair de alguns bairros de Fortaleza. Seria ousado dizer que o North Shopping é o shopping dos caucaienses. Portanto, a boa infraestrutura rodoviária e transportes coletivos eficientes que facilita 0 acesso da população de vários bairros de Caucaia, transforma esse shopping em locus de consumo e lazer para tal município.

A partir de nossas entrevistas pudemos caracterizar a área de influência imediata do North Shopping são os seguintes bairros: Presidente Kennedy, Monte Castelo, Parquelândia, Bela Vista ; Álvaro Weyne, Quintino Cunho, Antônio Bezerra e Pici em Fortaleza; e Cuapã, Parque Soledade, Potira, Tabapuá, Jurema/Marechal Rondom, Albano/Guadalajara, Araturi, Nova Metrópole e Icaraí em Caucaia.

\section{O North Shopping no contexto de integração metropolitana}

Geografia Ensino \& Pesquisa, v. 16, n.1, p. 55-70, jan.jun. 2012

O papel do North Shopping no processo de integração metropolitana de Fortaleza e Caucaia
O North Shopping na zona Oeste da capital localiza-se na avenida Bezerra de Menezes, que tem como continuação a BR 222, estrada federal que liga Fortaleza a Caucaia e à zona norte do estado e do país. Esta rodovia dá acesso também a CE-020 que articula a RMF com o sudoeste do Ceará. Aparentemente este shopping situa-se numa área periférica da cidade, mas 
com a expansão da malha urbana e dos meios de transporte, ele tornou muito acessível, não ficando muito distante do centro tradicional de Fortaleza.

Ao escolher este local, provavelmente o empreendedor não imaginou que este shopping fosse alcançar importância regional. Depois de sua inauguração, diante do sucesso e da demanda, este shopping passou por três reformas, com ampliação da variedade e do número de estabelecimentos e para isto foi necessário à ocupação de toda a área física do terreno e a verticalização.

O empreendedor ao decidir a implantação e localização de um grande equipamento, como o North Shopping contratou especialistas para avaliar a rentabilidade do investimento-potencial dos consumidores, pois o objetivo, na lógica do sistema capitalista é reprodução e acúmulo de capital. Com base nas teorias de localização, os especialistas antes de escolher 0 terreno onde será implantado o equipamento, eles pesquisam a potencialidade dos consumidores, se a localização tem bom acesso e se atende aos gostos e interesses da população da área de influência que pretendem atingir. Portanto, são levantados dados sobre o nível educacional, poder aquisitivo, hábitos, meios de transporte, dentre outros. $O$ sucesso de um empreendimento varejista como o shopping center depende da aceitação/atração da população, por este espaço de consumo e lazer.

O North Shopping tem uma boa aceitação do público, mostrando-se como um importante locus de consumo e lazer para setores da sociedade fortalezense, pois apresenta itens de segurança, conforto, comodidade, vendidos através de campanha publicitária. Desta forma, este shopping é de grande relevância, primeiramente para os bairros em seu entorno, como também atinge também moradores do município de Caucaia que se sentem atraído por este templo de consumo.

Santos (1996) destaca o papel da acessibilidade ao centro comercial e, portanto a escolha de uma localização estratégica do ponto de vista de consumidor. No que tange à relação entre acessibilidade e mobilidade urbano-metropolitana entre os municípios da RMF é realizada, através de transportes particulares e públicos, contribuindo para impulsionar a integração metropolitana entre Fortaleza-Caucaia.

A mobilidade diária da população gera movimentos pendulares os quais se realizam em função da dissociação entre local de moradia e local de trabalho e de estudo. 0 movimento pendular ocorre diante da necessidade de buscar novos lugares, inclusive novos espaços de compras e lazer. Desta forma surgem novos equipamentos de consumo, como o North Shopping que incentivam tais fluxos.

De acordo com Pequeno (2009), Caucaia tem um elevado nível de integração, pois alguns fatores favorecem a intensidade de relações espaciais, sociais, que são percebidas pelos fluxos entre estes dois municípios. 0 processo de conurbação está ocorrendo entre Fortaleza e Caucaia, Com a expansão da malha urbana de Fortaleza houve um transbordamento de atividades econômicas (indústria, lazer, etc.) e habitações para municípios vizinhos, dentre esses Caucaia, havendo a junção física de áreas urbanas, configurando um processo denominado de conurbação. A partir deste fenômeno, ampliaram-se as relações entre os municípios. Ruas, avenidas e pontes são construídas para interligar estes municípios que são atendidos por linhas regulares de ônibus. Instala-se uma rede comum de saneamento básico, de energia elétrica e atendimento hospitalar. Todos esses aspectos vão caracteriza a dinâmica do espaço metropolitano.

Nesse contexto, o North Shopping tem atraído moradores de Caucaia que se deslocava para Fortaleza, com o objetivo de trabalho, estudo ou busca de outros tipos de serviços. 0

Geografia Ensino \& Pesquisa, v. 16, n.1, p. 55-70, jan.jun. 2012.

Gonçalves; T. E.; Costa, M. C. L. 
shopping climatizado, seguro, com luzes e cores conduz os passantes a realização de compras e usufruir das atividades de serviços.

Este shopping através das atividades terciárias torna-se um ponto estratégico na relação Fortaleza-Caucaia na rede urbano-metropolitana. A localização e os atributos elencados pelos frequentadores nas entrevistas fazem com que o North Shopping detenha uma parcela significativa de consumidores provindos do município de Caucaia.

\section{Conclusão}

Os shoppings tiveram grande aceitação no Brasil, alterando os hábitos da sociedade urbana. Estes espaços comerciais multiplicaram-se na última década. Cresceu o número de shoppings e mais ainda o número de frequentadores. Este equipamento comercial encontrou na cidade seu locus de desenvolvimento e influenciou a cultura de consumo.

Neste contexto, nos propomos nesta pesquisa entender o papel do North Shopping como elemento de integração metropolitana Fortaleza-Caucaia. O poder de atração deste shopping é justificado por vários atrativos como: fácil acesso, presença de estacionamento, segurança, conforto e a quantidade e qualidade dos equipamentos, serviços e produtos ofertados.

Na pesquisa constatamos que a área de influência deste shopping ultrapassa os limites da capital, polarizando bairros de Caucaia, principalmente, os conjuntos habitacionais de Tabapuá, Nova Metrópole, Araturi e de Jurema.

Os moradores de classe média que transformaram as casas de veraneio em definitivas (Icaraí, Tabuba, Cumbuco) adotam este shopping como espaço de compras, pela proximidade de suas habitações, como também pelos produtos oferecidos.

O movimento pendular é intenso e quase todas as linhas de ônibus e automóveis particulares provindos de Caucaia em direção ao Centro de Fortaleza passam em frente ao North Shopping. Muitos aproveitam a oportunidade para comprar e se divertir.

Sobre seus frequentadores destacamos os jovens de Caucaia, bem como os estudantes universitários da Universidade Federal do Ceará e de escolas públicas e privadas, o shopping é lugar de encontro e de festa. Talvez isto explique a forte presença de jovens entre os frequentadores. Muitas vezes não vão comprar mercadorias, mas divertir-se neste espaço de lazer.

Portanto, consideramos que o North Shopping tem contribuído para fortalecer os laços de Fortaleza e Caucaia, favorecendo a intensificação de movimentos pendulares em função não só do trabalho e da escola, mas também do lazer, do comércio e de outros serviços.

Os dados encontrados em nossas entrevistas, levantamentos bibliográficos e documentais explicam o papel do North Shopping na integração metropolitana de Caucaia e Fortaleza, assim como o North Shopping se afirma em um espaço de consumo e lazer, que cada vez mais tem ampliado a sua zona de influência para fora da capital.

Geografia Ensino \& Pesquisa, v. 16, n.1, p. 55-70, jan./jun. 2012

O papel do North Shopping no processo de integração metropolitana de Fortaleza e Caucaia

\section{Referências Bibliográficas}

AMORA, ZenildeBaima. 0 espaço urbano cearense: breves considerações. In. AMORA, Z. B.(org). O Ceará: enfoques geográficos. Fortaleza: Funece, 1999. 
ANDRADE, Manuel Correia de. Espaço, Polarização e Desenvolvimento. 5ª ed. Editora: Atlas, 1987.

BERNAL, Maria Cleide Carlos. A Emergência de Fortaleza como metrópole periférica: Segregação e terceirização. Tese de Doutorado. UFRJ, 2003.

CARLEIAL, Adelita Neto. Transições Migratórias. Fortaleza.: Iplance, 2001.

CARLOS, Ana Fani Alessandri. A cidade. São Paulo: Contexto, 1997.

CARLOS, Ana Fani Alessandri. Espaço urbano: Novos escritos sobre a cidade. São Paulo: Contexto, 2004.

CARVALHO, Madalena Grimaldi de. A difusão e a integração dos Shoppings Centers na cidade: As particularidades do Rio de Janeiro. Rio de Janeiro/ UFRJ tese de doutorado, 2005.

CLARK, David. Introdução à geografia urbana. São Paulo: Difel, 1982.

CORRÊA, Roberto Lobato. Região e organização espacial. São Paulo: Ática, 1988.

CORRÊA, Roberto Lobato. 0 Espaço urbano. São Paulo: Ática, 1999.

CORRÊA, Roberto Lobato. A Rede urbana. São Paulo: Ática, 1989.

COSTA, Maria Clélia Lustosa da. Cidade 2000: expansão Urbana e segregação espacial em Fortaleza. São Paulo, FFLCH/USP, dissertação (mestrado).

COSTA, Maria Clélia Lustosa da.Fortaleza: expansão urbana e organização do espaço. In. SILVA, José Borzacchiello da (org.). CAVALCANTE, Tércia Correia (org.) DANTAS, Eustógio Wanderley Correia (org.). Ceará: um novo olhar geográfico. Fortaleza: Edições Demócrito Rocha, 2005.

COSTA, Maria Clélia Lustosa da.Urbanização da sociedade cearense. In. DAMIANI, Amélia Luisa, CARLOS, Ana Fani Alessandri (orgs.). 0 espaço no fim do século: a nova raridade. $2^{\mathrm{a}}$ ed. São Paulo: Contexto, 2001.

DAMIANI, Amélia Luisa. População e Geografia. São Paulo: Contexto, 1991.

LENCIONI, Sandra. Uma nova determinação do urbano: o desenvolvimento do processo de metropolização do espaço. In. CARLOS, Ana Fani Alessandri.(org.). LEMOS, Amália Inês Geraiges. (org.). Dilemas Urbanos - Novas Abordagens sobre a cidade. São Paulo: Contexto, 2003.

LIPIETZ, Alain. 0 capital e seu espaço. São Paulo: Nobel, 1988.

MARX, Karl. 0 capital. Rio de Janeiro: Civilização Brasileira, 1986

OLIVEIRA, Marúcia Coutinho Chaves. Shoppings centers, espaços de lazer, de encontros e de consumo: o caso do lguatemi -Fortaleza. Monografia (Curso de Geografia). Universidade Federal do Ceará, 2007.

OBSERVATÓRIO DAS METRÓPOLES. Identificação dos espaços metropolitanos e construção de tipologias: relatório da atividade 1. S.I., 2004. Projeto Análise das Regiões Metropolitanas do Brasil. Contrato Ministério das Cidades, FASE. Trabalho realizado por IPPUR, FASE, IPARDES.

PADILHA, Valquíria. Shopping center: a catedral das mercadorias. São Paulo: Boitempo Editorial, 2006.

PEQUENO, Luis Renato Bezerra (org.). Como anda Fortaleza. Rio de Janeiro: Letra Capital: Observatório das Metrópoles, 2009.

PINTAUDI, Silvana Maria; FRÚGOLI JÚNIOR, Heitor (orgs). Shopping Centers: Espaço, Cultura e Modernidade nas cidades brasileiras. São Paulo: Editora Estadual Paulista, 1992.

PINTAUDI, Silvana Maria. Cidade, cotidiano e imaginário. In: SILVA, José Borzacchiello da; COSTA, Maria Clélia Lustosa da; DANTAS, Eustógio Wanderley C orreia (org.). A cidade e o urbano. Fortaleza: EUFC 1997.

Geografia Ensino \& Pesquisa, v. 16, n.1, p. 55-70, jan.jun. 2012. 
de revitalização do centro de Fortaleza. In SILVA, José Borzacchiello da. (org.). $4^{\circ}$ Simpósio Nacional de Geografia Urbana. Fortaleza: Nutec, 1995

SANTOS, Milton. A Urbanização Brasileira. 4ª ed. São Paulo: Hucitec, 1996.

SANTOS, Milton. Metamorfose do espaço habitado. $5^{\text {a }}$ ed. São Paulo: Hucitec, 1998.

SANTOS, Milton. A natureza do espaço: técnico e tempo, razão e emoção. São Paulo: Hucitec, 1996.

SANTOS, Milton. Manual de Geografia Urbana. 2a ed. São Paulo: Hucitec, 1989.

SILVA, José Borzacchiello da. Reinventando Fortaleza: o saber geográfico e outros saberes na interpretação da cidade. In CARLOS, Ana Fani Alessandri. (org.). Os caminhos da reflexão sobre a cidade e o urbano. São Paulo: Edusp, 1994.

SILVA, José Borzacchiello da. A região metropolitana de Fortaleza. In SILVA, José Borzacchiello da (org.). CAVALCANTE, Tércia Correia (org.) DANTAS, Eustógio Wanderley Correia (org.). Ceará: um novo olhar geográfico. Fortaleza: Edições Demócrito Rocha, 2005.

SILVA, José Borzacchiello da. Novos Desafios para as Grandes Cidades Brasileiras. Revista CCHLA/UFRN Natal v. 10 n. $1 / 2$ jan/dez 96.

SPÓSITO, Maria Encarnação Beltrão. Capitalismo e urbanização. 4 ed. São Paulo: Contexto, 1991.

SPÓSITO, Maria Encarnação Beltrão. A gestão do território e as diferentes escalas da centralidade urbana. Revista Território, ano III, nº 4, 1998.

SOUZA, Maria Salete. 0 crescimento das cidades no Ceará e sua evolução. In SILVA, José Borzacchiello da. (org.) $4^{\circ}$ Simpósio Nacional de Geografia Urbana. Fortaleza, 1995.

\section{Endereço para Correspondência}

Tiago Estevam Gonçalves - Instituto Federal de Educação, Ciência e Tecnologia do Ceará. Rodovia CE 292, km 15. Gisélia Pinheiro. 63115-500 - Crato, CE - Brasil - Caixa-Postal: 35868115

E-mail: tiagoestevam1@yahoo.com.br

Recebido em 26 de agosto de 2011

Revisado pelo autor em 14 de outubro de 2011

Aceito em 13 de novembro de 2011

Geografia Ensino \& Pesquisa, v. 16, n.1, p. 55-70 